\title{
RÉGIS DEBRAY E OS ESTUDOS DO DISCURSO: contribuições midiológicas para o conceito de suporte discursivo
}

Vitor Vieira Ferreira

(Universidade Federal do Rio de Janeiro) https://orcid.org/0000-0002-5983-614X

\section{RESUMO:}

O presente artigo possui dois objetivos específicos e que estruturarão nosso texto. Em primeiro lugar, apresentaremos a midiologia de Régis Debray, destacando-lhe alguns de seus aspectos, postos em seguida em interface com os Estudos do Discurso. Em segundo lugar, a partir do conceito de suporte presente nas obras do autor francês, desenvolveremos teoricamente à luz dos Estudos do Discurso o conceito de suporte discursivo e sustentaremos sua relevância como uma ferramenta de análise que seja cara à análise do discurso.

PALAVRAS-CHAVE: Régis Debray, midiologia, Estudos do Discurso, suporte discursivo.

\section{RÉGIS DEBRAY AND DISCOURSE STUDIES: mediology's contributions to the concept of discursive support}

\section{ABSTRACT:}

The present article is structured in two main sections. In the first section we aim to present an outline of Régis Debray's mediology, in order to highlight some aspects of his discipline and relate them to Discourse Studies. In the second section we intend to develop the concept of discursive support theoretically from a Discourse Studies perspective and taking into account Debray's notion of support. In this section it will also be argued 
why the concept of discursive support could be a relevant tool in the field of discourse analysis.

KEYWORDS: Régis Debray, mediology, discourse studies discursive support.

\section{1 lntrodução}

Refletir sobre a linguagem em suas situações concretas de uso, historicamente situadas e determinadas, em diferentes graus por instâncias extralinguísticas da vida social é o pressuposto primeiro para aqueles que pretendem se lançar ao campo dos Estudos do Discurso (doravante ED). Utilizamos esta rubrica, deliberadamente mais ampla, sem que se queira esmaecer ou eliminar as diferenças verificadas entre as mais diversas correntes teóricas (de Bakhtin a Benveniste, de Pêcheux a Fairclough) e seus respectivos autores; para uma exposição geral e mais ampla sobre o tema ver Iñiguez (2004). Tais pontos de divergências e convergências certamente nos convidam a um produtivo debate, ao qual, contudo, não nos propomos aqui. Isto, pois o que mais nos interessa, à guisa de introdução, é a exigência de se conceber o fenômeno linguístico circunscrito não exclusivamente por seus princípios de estruturação interna, mas enquanto algo que reflete e ao mesmo refrata o contexto social mais amplo pelo qual é engendrado - nos remetendo aqui à reflexão bakhtiniana. Isto corresponde, tacitamente, à pressuposição ontológica de ser a linguagem socialmente determinada (conquanto não exclusivamente, pois não nos esqueçamos do complexo biológico que garante a um ser humano a faculdade da linguagem) e que nos leva, a nosso ver, à exigência metodológica de que nossa empreitada científica recorra, em maior ou menor grau, a disciplinas que não tomem a linguagem como seu objeto central de estudo e análise (ainda que a perpassem de alguma forma e com algum nível de importância). Falamos aqui, portanto, do caráter fundamentalmente interdisciplinar que um trabalho sob a rubrica dos ED tende a apresentar.

Neste sentido, o presente texto tem por um de seus objetivos apresentar, dentro de seus respectivos limites, algumas reflexões e perspectivas presentes em parte da obra de um nome que não 
costuma figurar entre os trabalhos de nosso campo. Trata-se de Régis Debray e mais especificamente de sua midiologia. Assim, dedicaremos a primeira seção de nosso texto após esta introdução a uma breve contextualização biográfica do autor, bem como a uma apresentação geral dos principais pontos selecionados por nós de sua midiologia, para em seguida refletir sobre sua pertinência para pesquisadores de nosso campo.

Sustentamos aqui que a midiologia, uma vez submetida ao olhar interessado dos ED, nos fornece bases teóricas para acrescentar ao conjunto dos conceitos relevantes e já conhecidos do campo o conceito de suporte discursivo. Caberá, por conseguinte, à segunda seção deste trabalho a tarefa de expor como a ideia de suporte se faz presente na reflexão midiológica para, em seguida, adjetivando-o com o termo "discursivo", concebê-lo como uma categoria produtiva para a análise do discurso (doravante $A D$ ). Que se esclareça, registramos aqui a expressão "análise do discurso" com letras minúsculas de modo a denotar o exercício científico de análise sem uma menção específica à Análise do Discurso Francesa ou a Análise Crítica do Discurso). Dedicaremos ainda nesta segunda seção algumas linhas a uma breve revisão bibliográfica do tema considerando o que já se produziu por outros autores sobre o conceito de suporte.

Ciente da complexidade inexorável que apresentam tanto a obra de Debray (e uma respectiva proposta de apresentação) quanto a reflexão teórica e conceitual sobre o suporte discursivo, não é demasiado reiterar que as ideias aqui apresentadas não se pretendem últimas quanto aos temas e que determinados aspectos e reflexões foram deliberadamente deixados de lado em função daquilo que consideramos, por ora, ser de maior relevância. As lacunas aqui observáveis (inexoráveis a e inalienáveis de qualquer texto) pretendemos que sejam justificadas por uma questão de economia textual e não por pressuposta irrelevância de nossa parte.

\section{Régis Debray e sua midiologia}

Régis Debray, nascido em 2 de setembro de 1940 em Paris, é uma proeminente figura intelectual na França e autor de uma extensa obra que perpassa os campos da Literatura e das Artes, da Filosofia e 
da religião, da política e mais destacadamente da midiologia; disciplina por ele fundada e que será objeto de nossas reflexões.

Além de inúmeros artigos, ensaios, panfletos políticos e novelas, Debray publicou vasta quantidade de livros e alguns destes tiveram suas versões traduzidas para o português; dentre os quais Curso de midiologia geral (1993), Vida e morte da imagem: uma história do olhar no Ocidente (1993), O Estado sedutor: as revoluções midiológicas do poder (1994) e Manifestos midiológicos (1995). Um dos períodos mais lembrados em sua biografia foi sua atuação junto a Che Guevara como guerrilheiro no Ejército de Liberación Nacional de Bolivia, o que acabou resultando em sua prisão na Bolívia durante os anos de 1967 a 1971. Debray despertara a atenção do próprio Fidel Castro, com quem manteve uma relação próxima, e sua atuação na América Latina serviu de matéria-prima para sua obra Révolution dans la Révolution? Lutte armée et lutte politique en Amérique latine (1967). Sua atuação in loco e suas ideias revolucionárias ecoaram também em terras brasileiras e Debray tornou-se conhecido à época, sobretudo pelos marxistas, tendo sido inclusive publicada no Brasil uma versão traduzida de seu Révolutions dans la Révolution?, em 1967. Ao longo das décadas de 80 e 90 esteve ainda à frete de diversos cargos de Estado; destacando-se no papel de membro do Conselho de Estado (Conseil d'État) da França entre os anos de 1985 a 1992.

Foi ao longo da década de 90 que o escritor e filósofo francês se dedicou à fundação da chamada midiologia; termo que já havia sido cunhado em 1979 e figurou na obra Le pouvoir intellectuel en France (1979), publicada em Paris. Foi, porém, com a publicação da obra fundadora intitulada, à semelhança saussuriana, de Cours de Médiologie générale (1991) que a midiologia se apresenta como uma disciplina autônoma.

No Brasil, a despeito de estarem disponíveis versões em português de algumas obras de Debray dedicadas exclusivamente à midiologia, a disciplina ainda não foi objeto de um estudo aprofundado e sistemático ou de um conjunto de iniciativas de maior destaque para a promoção e difusão de suas ideias - registre-se aqui, como exceção, o trabalho de Kalume (2008).

$\mathrm{O}$ presente texto, por sua vez, que se restringe à midiologia de Debray, pretende, ainda que de forma discreta, integrar o modesto conjunto de trabalhos publicados no país sobre o pensador francês. 
Não tão somente por se tratar de um importante nome da intelectualidade francesa, mas sobretudo - assim pretendemos sustentar - pela relevância de suas ideias para os ED.

Tratemos então de modo sucinto e não exaustivo de alguns traços característicos da midiologia. Tão logo nos deparamos com o termo, decompomos sem maiores dificuldades o neologismo: temos, assim, "mídia" e "logos". Quanto ao último, não há maiores dificuldades em apreender seu sentido. Já quanto ao primeiro, temos, em língua portuguesa, uma ambiguidade: o termo "mídia" pode significar tanto o suporte material por meio do qual uma mensagem é transmitida, quanto, por extensão metonímica, o conjunto mais amplo dos meios de comunicação de massa. Nenhum dos sentidos, no entanto, corresponde ao sentido que "midio-" assume na obra de Debray.

A midiologia não se apresenta, como poderia se supor em um primeiro momento, como o estudo dos elementos materiais desenvolvidos pelo ser humano e que servem de suporte para a transmissão de mensagens; bem como não se trata aqui também de um estudo dos meios de comunicação de massa. Ela se propõe a ser um estudo das "vias e meios da eficácia simbólica" (DEBRAY, 1995 , p.16); isto é, nos termos de Vandenberghe (2007, p. 26), um "estudo das condições materiais e sociais da transmissão da cultura e, assim, da produção e da reprodução da sociedade". Tais vias e meios simbólicos de transmissão e circulação compõem, por sua vez, um conjunto que "precede e supera a esfera dos meios de comunicação de massa contemporâneos" (DEBRAY. 1993, p. 15). Sintetiza, portanto, o autor afirmando que "[n]a midiologia, 'midio' não significa mídia nem médium, mas mediações, ou seja, o conjunto dinâmico dos processos e corpos intermédios que se interpõem entre uma produção de signos e uma produção de acontecimentos" [grifo do autor] (DEBRAY, 1995, p. 28-9).

O termo "médium" carece aqui de esclarecimento. Para Debray, o "médium" é um vetor de transmissão que pode ser entendido em quatro sentidos: como um procedimento geral de simbolização, como um código social de comunicação, como um suporte material e como um dispositivo de gravação conectado a uma determinada rede de difusão (DEBRAY, 1995, p. 23). Esta complexa trama de sentidos atribuídos ao termo nos leva a compreendê-lo não como uma coisa física, um artefato, um produto 
tecnológico, mas como um processo dialético e dinâmico que integra e inter-relaciona objetos, pessoas e textos (VANDENBERGHE, obra citada, p. 29). Assim, mesmo uma "mesa de refeição, um sistema de educação, um café-bar, um púlpito de igreja", conquanto não se encaixem na definição tradicional de mídia supracitada, podem ser entendidos como um médium e "entram no campo da midiologia enquanto espaços e alternativas de difusão, vetores de sensibilidades e matrizes de sociabilidades" (DEBRAY, 1993, p. 15).

Em suma, a midiologia se ocupa de um conjunto de relações, e não de um conjunto de meios de comunicação, cujas qualidades intrínsecas lhe são relevantes apenas se observadas em um contexto mais amplo no qual tais meios sejam em sua materialidade componentes de uma dimensão do processo de transmissão simbólica (cf. DEBRAY, 2001, p. 99).

Estabelecido o objeto de análise da midiologia, Debray argumenta que os fatos observáveis da transmissão simbólica não receberam a devida atenção por parte de disciplinas já estabelecidas à sua época; o que concederia à midiologia as condições para justificar e pleitear sua autonomia. Debray o faz em diversos momentos de suas obras; inclusive de modo sistemático, como se observa nas perguntas que dão título, respectivamente, a cinco seções de um dos capítulos de sua Introduction à la médiologie (1999): "por que não somos semiólogos?"; "por que não somos psicólogos?"; "por que não somos sociólogos?"; "por que não somos (ou não unicamente) pragmatistas?" e "por que não somos (não todos ou não totalmente ou não todavia) historiadores?". Similarmente, observam-se ainda em outros momentos paralelos com a sociologia da cultura, história das ideias, ciências políticas (cf. DEBRAY, 1993, p.14), com a história das mentalidades (cf. idem, p. 54) e mesmo com a linguística saussuriana (cf. idem, p. 58).

É evidente que as limitações atribuídas por Debray a tais disciplinas em termos de seus objetos e de suas respectivas bases metodológicas demandariam um estudo mais aprofundado, sobretudo em virtude da quantidade autores e obras relacionadas às quais o autor francês faz menção. Não obstante, de modo geral e para nossos fins de exposição, podemos argumentar que a justificativa central para a autonomia da midiologia reside no fato de que nenhuma das disciplinas mencionadas previamente assume especificamente como objeto as bases materiais e tecnológicas do 
universo simbólico por meio das quais se realiza a interface entre o mundo espiritual e o material (cf. VANDERBERGHE, obra citada, p. 28).

A relação entre estas duas dimensões da experiência humana - uma material, que abarca o conjunto de suas produções técnicas e tecnológicas, e outra espiritual, que diz respeito aos sentidos, às ideias e à cultura - é uma das linhas centrais para a midiologia. Esta toma como princípio o fato de haver uma interrelação entre o fato técnico e o fato cultural, visto que "[a]trás de toda subjetividade coletiva, há um ou vários sistemas técnicos e vice-versa. Do mesmo modo que não existe autonomia do fato técnico, também não há autonomia do fato cultural" (DEBRAY, 1995, p. 148). Disciplinas e correntes teóricas que pressuponham esta autonomia dos sentidos, das ideias ou das culturas, não estão em condições, portanto, de contemplar o complexo da mediação, tornada então, como visto, o objeto específico da midiologia.

A afirmação de que "[a]s ideias não pegam nas pessoas pelas mãos" (DEBRAY, 1993, p.22), reflete a postura ontológica materialista que assume a empreitada midiológica e que implica na exigência metodológica de se avaliar a produção espiritual em estreita vinculação com as condições materiais e técnicas que a engendram. De modo que, diante de uma produção simbólica qualquer, para além de sua estruturação interna, o midiólogo deve se perguntar: "de que maneira isso se transmite, difunde, circula, propaga, multiplica, etc.? Sobre que tipo de suporte? Que é que isso modifica e recompõe no corpo dos transmissores e receptores? Através de que vetores? Que tipo de percursos, redes, alianças, confluências, saídas, etc." (idem, p.36)? Deixar estas questões de lado, ignorando com isso as leis que regem a transmissão simbólica, nos leva à falsa crença de que são as ideias que governam o mundo (cf. idem, p. 171) e que desconsidera a inalienável rede de transmissão socialmente estruturada por meio da qual estas ideias se fazem presentes.

Sob a perspectiva midiológica, o social simbólico e o material técnico não formam duas classes distintas da realidade, mas sim uma mesma dimensão que contempla sujeitos e objetos, elementos humanos e não-humanos, que se imiscuem e estabelecem entre si mutuamente ordens de determinação (cf. VANDENBERGHE, obra citada, p. 28). Ademais, a importância que o objeto técnico assume 
dentro do pensamento midiológico é tal a ponto de que se postule caber à técnica o papel de fundação ontológica do próprio homem. Debray passa então a caminhar por entre os campos de uma filosofia da tecnologia, na medida em que afirma que

[...] a técnica, prosseguimento da vida por outros meios, serviu como força motriz para a hominização como chave do desligamento zoológico: enquanto o animal permanece geneticamente programado, colado a um código orgânico, fixo e especializado, a etnicidade humana descola da especificidade das memórias biológicas. $\mathrm{E}$ isso acontece graças ao movimento contínuo de exteriorização das faculdades individuais nesses órgãos inorgânicos que são os utensílios, depois as máquinas e, em seguida, as tecnologias (atualmente, memória e cálculo excorporificam-se na inteligência artificial) (DEBRAY, 1995, p. 150-1).

Esta importância concedida por Debray aos meios técnicos pelos quais se dá a transmissão simbólica, porém, não deve ser compreendida como uma forma de determinismo tecnológico. Como visto, não se trata de postular aqui a autonomia absoluta do objeto técnico, conquanto o interesse que a midiologia possui por este seja seu traço característico mais distintivo. Fato é, segundo Debray, que os meios de transmissão estão sujeitos às suas próprias leis internas derivadas de sua própria natureza e que suas transformações escapam aos controles da vontade humana. Acrescente-se a isso a constatação de que "a técnica é o lugar do progresso" (DEBRAY, 2001, p.85) [tradução própria] e que a evolução do médium se dá com base no imperativo de que seja dominante aquele "mais eficiente, isto é, aquele cuja relação custo/eficácia é a melhor. Ou seja, aquele que se difunde de maneira mais ampla, mais rápida, com menores despesas para o emissor e o menor esforço para o receptor [...]" (DEBRAY, 1993, p. 319). Diante disto, Debray, em sua filosofia da tecnologia, não postula que esta última seja em si boa ou ruim; caberá ao midiólogo assumir o papel de um atento investigador dos objetos e vetores de transmissão simbólica e que se propõe a "definir as determinações objetivas das aparelhagens do pensamento que está tomando em consideração" (idem, p. 82). Não devemos, portanto, despejar nossas esperanças no progresso tecnológico em si - progresso esse, diz o autor (1995, p. 46), que não se apresenta 
como uma "epifania progressiva da liberdade" - ou na força das ideias por elas próprias - no sentido de que "[q]uando se está com a verdade ou então com o sentido da história [...] isso funciona por si só" (DEBRAY, 1993, p.25). Em meio a estas duas posturas, a midiologia estabelece como o imperativo a busca pela compreensão das estruturas de mediação que permeiam nossa vida social concreta para, precisamente uma vez de posse deste entendimento, suportar melhor, ou ao menos da forma mais consciente possível, as suas influências e determinações ao longo da história.

Diante desta breve exposição sobre algumas das linhas gerais da midiologia, podemos destacar determinados aspectos de convergência entre esta disciplina e os ED. Considerados ambos em uma perspectiva histórica mais ampla, destacaríamos, em primeiro lugar, que midiologia e os ED se constituíram a partir de uma "mudança de foco" no que diz respeito àquilo que se apresentava como central e aquilo que se apresentava como periférico diante de um determinado fenômeno que se pretende observar. Como vimos, Debray justifica a exigência de uma disciplina autônoma em virtude da pouca atenção dedicada aos meios técnicos de transmissão simbólica por parte de outras disciplinas. Estas, segundo o autor, preocupadas com as leis do sentido e dos signos, com os fatos da linguagem, com as mentalidades, enfim, com a dimensão espiritual da atividade humana teriam cedido à ilusão de "pensar a história das culturas ou das instituições como independente dos sistemas técnicos" (DEBRAY, 1993, p.76). Coube precisamente a estes sistemas técnicos, compreendidos como sistemas de transmissão simbólica, um papel central na midiologia.

Observado isto, há de se estabelecer um paralelo com a trajetória da Linguística moderna desde a sua fundação com Saussure até seu atual estado. Já no Cours de linguistique générale (1916) são postos em questão os dois caminhos possíveis a serem tomados pelo linguista diante de seu objeto de análise: o da linguística interna e o da linguística externa. Seguindo a metáfora de Saussure (2006, p. 32), ora nos dedicamos às regras internas do jogo de xadrez que regulam a interação entre cada uma de suas peças, ora nos ocupamos do formato, do material das peças do tabuleiro, do local onde foram produzidos etc. Desde a referida obra, passou-se algum tempo até que os linguistas passassem a tomar as circunstâncias extradiscursivas como elementos fundamentais para a 
compreensão dos fenômenos linguísticos; realizando-se assim o que se poderia chamar de giro discursivo. E sobre isso afirma Dijk:

Enquanto o estudo da gramática independe do contexto que, em um determinado momento, era proeminente, passou a se restringir quase que totalmente a uma pequena área da linguística, vemos que não só as demais áreas dessa disciplina como também a maioria das outras disciplinas nas humanidades e nas ciências sociais se voltaram para os problemas fascinantes do texto e da conversação em interação, cognição, contexto social ou cultura (2005, p. 7).

Conceitualmente, a frase isolada, decomposta em seus elementos constituintes e suas dimensões fonológicas, morfológicas, sintáticas e semânticas deu lugar ao discurso.

Portanto, estabelecido o paralelo, podemos dizer que assim como as ideias, numa perspectiva midiológica, não poderiam ser pensadas sem que se levasse em conta seus vetores de transmissão, também o fenômeno linguístico passou a ser pensado não mais como algo isolado das dimensões culturais, sociais e políticas que o engendram. Depreende-se daí uma exigência metodológica interdisciplinar comum tanto aos ED quanto à midiologia (cf. DEBRAY, 1995, p. 141), justificada pelo grau de determinação exercido sobre seus objetos por dimensões que lhes escapam, mas devem, não obstante, serem levadas em consideração na prática de investigação científica.

Neste sentido não é descabido dizer que um estudo midiológico pode tomar como contribuição para si a ideia de que um fenômeno discursivo seja ele próprio visto como um vetor de transmissão simbólica. Os ED, por sua vez, como veremos à frente, podem compartilhar desta atenção especial dada aos suportes técnicos pressuposta pela midiologia. Esta atenção justifica-se ainda com maior intensidade se nos remetermos à perspectiva de "mudança social" postulada pela Análise Crítica do Discurso (cf. FAIRCLOUGH, obra citada). Isto, pois, conforme sustenta Debray, "uma teoria da 'mudança social' já não pode se dissociar, como conteúdo válido em si, das formas e condições materiais de sua transmissão" (DEBRAY, 1993, p. 320).

Midiologia e ED compartilham ainda uma mesma perspectiva materialista sobre os fenômenos analisados, tanto pela midiologia 
quanto pelos ED (cf. PÊCHEUX, 2014, p. 127; 1997, p. 89). Como vimos, para além da mera atenção dada aos meios materiais de transmissão, Debray postula que tanto estes quanto as ideias, o espírito, a cultura estão em mesmo nível de realidade, sem que haja qualquer corte ontológico entre estas duas dimensões. Sobre o que, afirma Debray (1993, p. 99) categoricamente que "[a] midiologia, essa física do pensamento social, é e continuará sendo materialista até o fim".

Em virtude da extensão deste nosso trabalho, nos limitamos a estes aspectos mais gerais com a conviç̧ão de que novas frentes de diálogo são possíveis de serem estabelecidas entre os dois campos em questão. Na seção seguinte trataremos de modo um pouco mais aprofundado do conceito de suporte discursivo, considerando a contribuição de Debray e sua midiologia para o desenvolvimento do conceito.

\section{0 conceito de suporte discursivo}

O termo "suporte" figurou em uma das passagens supracitadas e nela ele se apresentava, segundo Debray, como um dos componentes do multifacetado termo "médium". Neste sentido, destacado o caráter de sua materialidade, ao suporte corresponderia $\mathrm{o}$ elemento mais concreto no qual um determinado conteúdo simbólico é registrado. Enquanto componente do médium, ao suporte também não era dada, por extensão, a devida atenção por parte das outras disciplinas, visto por estas como algo de menor relevância. Em tom crítico, Debray afirma, por exemplo, que "o historiador que fale de coisas, materiais, velocidades, transportes, fabricações, utensílios fica logo fora da rubrica nobre 'história cultural' [...] e cai na rebarbativa e acessória "história das técnicas" (DEBRAY, 1993, p. 73). Como vimos, toda a midiologia funda-se a partir da centralidade das transmissões, do médium, do meio técnico e Debray em diversos momentos é enfático quanto à importância específica do suporte. Em suas palavras, "o suporte é, talvez, o que se vê menos e o que conta mais. Na civilização concebida como sistema de produção de vestígios, ele não representaria a força produtora, nem a fonte de energia, mas sim a matéria prima" (DEBRAY, 1993, p. 207). 
O conceito de suporte torna-se ainda mais relevante quando concebido em estreita relação com o conceito de midiasfera. Comentamos anteriormente que a produção técnica humana possui leis próprias e que, sobretudo a partir de uma perspectiva materialista, ela se transforma com o passar do tempo. A midiologia, de modo a não violar este regime de historicidade ao qual todo médium está submetido, assume um caráter de registro historiográfico; o que não nos permite interpretar a autonomia da midiologia frente à disciplina da História como uma total independência (cf. DEBRAY, 2001, p. 205). Coloca-se, portanto, como uma das questões de investigação as condições objetivas dos instrumentos e dos procedimentos de transmissão e registro simbólico em diferentes momentos da história humana. Debray amplia assim seu escopo de análise para além da contemporaneidade extrapolando o conjunto dos meios de comunicação de massa. Dirá o autor (1995, p. 61): "[h]á vários milhares de anos que se constitui o estoque mitológico da humanidade, em seu recôndito mais profundo; e o transporte da trama memorial de uma civilização através das épocas não foi feito pelos mass media".

É neste contexto de reflexão que se insere o conceito de midiasfera, definido como o conjunto mais amplo dos meios de transmissão e transporte de mensagens em um determinado recorte histórico. Uma midiasfera, que se estrutura a partir de seus suportes de registro e memorização, condiciona "um tipo de credenciamento dos discursos, uma temporalidade dominante e um modo de reagrupamento, ou seja, as três faces de um triedro formando [...] a personalidade coletiva ou o perfil psicológico característico de um período midiológico" (DEBRAY, 1995, p. 40). Os suportes, consideradas suas configurações específicas e as relações que estes estabelecem com os meios de transmissão em um determinado momento histórico, para além de meros componente de inscrição simbólica são, portanto, de profunda relevância para compreendermos a midiasfera de uma época e as crenças, estilos, personalidades coletivas e regimes de velocidade por ela condicionados.

Conforme comentado anteriormente, os vetores de transmissão dos quais se ocupa a midiologia dizem respeito não somente a suportes que comportem um registro verbal, mas a tudo aquilo que se preste à transmissão simbólica. De modo mais 
específico, quando concebemos aqui o conceito de suporte discursivo (doravante $\mathrm{SD}$ ), nos referimos ao meio concreto e empiricamente observável que apresenta, especificamente, qualquer tipo de conteúdo verbal nele registrado. Ademais, a adjetivação por meio do termo "discursivo", além de especificar que o SD apresente em si um conteúdo de linguagem verbal, delimita o conjunto de suportes que se pretendem objetos de análise dos ED. Trata-se aqui, portanto, de uma restrição metodológica e de uma questão de filiação teórica: na medida em que um determinado elemento é analisado enquanto um suporte discursivo, supõe-se que este exercício de análise tenha como pressuposto teórico o conceito de discurso. Conceito este que, para além das especificidades de cada autor e filiação teórica, toma por conteúdo semântico fundamental a produção linguística efetiva, histórica e situacionalmente situada, bem como a relação desta com as instâncias extralinguísticas envolvidas nesta produção. Por outro lado, ao tomarmos como ponto de partida a ideia de suporte à luz da perspectiva midiológica, sustentamos que os aspectos a ela vinculadas - conforme apresentado anteriormente, sua materialidade, seu regime de historicidade, sua relação com a midiasfera, sua relevância para o estudo dos sistemas de transmissão de um momento histórico devem ser atribuídos ao conceito de SD.

Outros autores também se lançaram à reflexão sobre a noção de suporte e com estes gostaríamos por hora de estabelecer diálogo. Tanto na produção francófona (Análise do Discurso Francesa, doravante $\mathrm{ADF}$ ) quanto na anglófona (Análise Crítica do Discurso, doravante ACD), temos como texto que mais se aproxima da pretensão de nosso trabalho de postular o SD como uma categoria de análise para a $\mathrm{AD}$ o capítulo "Mídium e Discurso" em Análise de textos de comunicação (1998) de Dominique Maingueneau (2004). Ainda que de forma não aprofundada, o autor afirma a relevância de se observar no exercício de análise o modo de manifestação material dos discursos, seu suporte e seu modo de difusão. Ademais, visto como algo que não pode ser descrito como mero acessório, o suporte não é um meio neutro de transmissão de discurso, posto que este "imprime um certo aspecto a seus conteúdos e comanda os usos que dele podemos fazer" (idem, p. 71). Não é de se surpreender que o mídium (termo que pode ser inicialmente compreendido como equivalente ao "médium" de Debray) seja considerado por 
Maingueneau "uma dimensão essencial" se levarmos em conta que ele dedicara um verbete específico à midiologia em seu Les termes clés de l'analyse du discours (1996); no qual, inclusive, afirma-se que a análise do discurso tem por postulado a inseparabilidade do conteúdo do discurso e de seu médium (cf. MAINGUENEAU, 1996, p. 55).

No contexto da produção anglófona, a produção discursiva que toma por suporte os meios tradicionais de comunicação em massa, sobretudo a impressa escrita, constituem um fértil campo de análise, cuja quantidade de produções não justificaria que citássemos aqui esta ou aquela. De modo geral, a escolha por estes suportes em específico se justifica pelo seu poder de influência em sistemas de conhecimento, crenças, valores, relações sociais, identidades sociais, dentre outros (cf. FAIRCLOUGH, 1995, p. 2); o que em nenhum sentido contraria as reflexões midiológicas previamente apresentadas, pelo contrário, só as reforça. Caberia a nós por ora tão somente então reafirmarmos que uma reflexão sobre os suportes extrapola o conjunto dos mass media.

Em língua portuguesa, a noção de suporte figura entre diversos trabalhos que podem, dito de modo geral, ser em sua maioria vinculados mais à Linguística Textual do que às $\mathrm{ADF} e$ ACD. De modo mais específico, verifica-se ainda nestes uma preocupação recorrente de se estabelecer os limites e as relações entre as noções de suporte e o conceito de gênero textual \discursivo - conceito este, diga-se, que também figura como objeto de investigação da ACD, como se observa em Fairclough (2003). Abstemo-nos, porém, do debate complexo e fecundo em torno de tais relações em virtude dos limites de nosso texto.

Destes trabalhos em língua portuguesa, o primeiro texto ao qual nos remetemos propõe de igual modo uma discussão contemplando o conceito de gênero e vincula-se, segundo as autoras (ACOSTA \& RESENDE, 2014, p. 127), de modo transdisciplinar ao Realismo Crítico (que tem em Roy Bhaskar seu maior representante) e à ACD. Nesse texto, a expressão "suporte discursivo" é apresentada como um conceito próprio e que se define como "veículos, espaços físicos ou virtuais, sobre os quais os textos ocorrem, potencialmente ou como realização" (idem, p. 134). Assim definido, o conceito de SD não apresenta qualquer contradição com a reflexão que desenvolvemos aqui até então. As autoras, no entanto, 
pressupõem um distinto grau de determinação do suporte sobre seu conteúdo verbal específico, bem como a relação mais ampla do SD com os regimes de produção, circulação e consumo mais amplos característicos da midiasfera em questão, se comparado tal grau com aquele pressuposto pela reflexão midiológica. Isto pode ser verificado com base nas afirmações das autoras (obra citada, p. 136) de que: a) os suportes estão vinculados a práticas sociais e ordens de discurso e b) os suportes são elementos internos ao discurso. Por concebermos ser necessária uma acentuação deste grau de determinação ao $\mathrm{SD}$, cremos ser mais adequado afirmar que: a') o SD determina práticas sociais e ordens de discurso e b') estes dispõem de autonomia e são regidos e estruturados por leis internas não exclusivamente discursivas, conquanto seu propósito de transmissão verbal deva ser considerado. Indo além, com b', pretendemos recusar a interpretação de que um SD estabeleça uma relação de mera pertinência ao conjunto maior aqui chamado de "discurso"; o que equivaleria, a nosso ver e seguindo a linha de Debray, a priorizar a dimensão espiritual do fenômeno discursivo em função de sua materialidade técnica.

Em segundo lugar, bastante referenciado por seus trabalhos sobre gêneros, Luiz Antônio Marcuschi também apresenta contribuições para uma reflexão sobre suportes. Em seu Produção textual, análise de gêneros e compreensão (2009), o autor (2009, p. 173) dedica uma pequena seção à noção de suporte no contexto de uma reflexão mais ampla sobre gêneros textuais. Marcuschi aborda a questão inicialmente remetendo-se às ideias de Maingueneau - com base no mesmo texto supracitado do autor francês - para em seguida oferecer sua própria definição de gênero: "entendemos aqui como suporte de um gênero um locus fisico ou virtual com formato específico que serve de base ou ambiente de fixação do gênero materializado como texto" [grifo do autor] (idem, p. 174). Esta definição, como o próprio autor aponta, pressupõe os aspectos a) da materialidade do suporte, b) de seu formato e c) de sua função de fixar o texto. Quanto aos dois primeiros aspectos, também não se observa qualquer divergência quanto ao conceito de SD conforme o supomos aqui. Já quanto ao último, por sua vez, Marcuschi afirma que "a função básica do suporte é fixar o texto e assim torná-lo acessível para fins comunicativos" (idem, p. 175). Parece-nos problemático, no entanto, e incompatível com a perspectiva de 
Debray que nos serve de base, caracterizar o SD como um elemento subserviente ao texto nele registrado, cuja única função é ser um instrumento operacionalizado no momento da comunicação. Neste sentido, também se aplicam aqui os comentários feitos acima quanto a Acosta \& Resende no que diz respeito aos distintos graus de determinação por parte dos SD quanto a seu conteúdo verbal e mesmo quanto às suas possibilidades de recepção e circulação.

Outra contribuição de destacada importância para o estudo dos suportes está presente em Tavora (2008), com sua tese de doutorado intitulada Construção de um conceito de suporte: a matéria, a forma e a função interativa na atualização de gêneros textuais. Após longo percurso de cotejamento entre autores e perspectivas que se lançaram à questão do suporte, o autor conclui seu trabalho com a proposta de um conceito de suporte que tem a matéria como uma de suas categorias fundamentais. Quanto a esta, o autor sustenta "que podemos aferir se a mobilização de um valor atribuído à matéria é um fator produtivo ou não no sistema de construção de sentidos, no entanto, tal mobilização não pode ser descartada, ou considerada inexistente" (idem. s.p.). Esta passagem ilustra a perspectiva subjacente à tese de que a materialidade de um suporte contribui para delimitar tanto a natureza de seus registros semióticos (linguagem verbal ou não-verbal), quanto as interações discursivas e não-discursivas por ele previstos e possibilitados, assim como exerce influência sobre a produção, circulação e recepção de seus conteúdos.

Feitas estas considerações, de modo a complementar a definição de SD que trouxemos nos parágrafos iniciais, gostaríamos de sintetizar aqui algumas proposições que dizem respeito ao conceito, de modo a elevá-lo ao nível de uma categoria relevante para a $\mathrm{AD}$. São elas: 1) um $\mathrm{SD}$ não é um mero artefato técnico subserviente ao propósito da transmissão de uma mensagem em uma interação comunicativa - assim como a linguagem hoje também já não é mais vista como um meio neutro de transmissão de ideias; 2) um SD é regido por suas leis internas e está vinculado a sistemas sociais extradiscursivos e contextos institucionais mais amplos que prescrevem e constituem a sua materialidade; 3) um SD exerce um efeito de determinação sobre a produção, circulação e recepção dos conteúdos verbais por ele veiculados; cabendo ao pesquisador estabelecer a medida e relevância deste efeito de determinação em 
cada contexto particular de investigação; 4) um SD, enquanto elemento constitutivo de uma midiasfera, assume o papel de uma das variáveis determinantes para a formação, desenvolvimento e manutenção das formas de consciência, mentalidades e visões de mundo de uma sociedade em um determinado momento histórico. Em suma, atribuir a um SD sua devida relevância equivale a refletir sobre os esforços humanos que, ao longo da história, foram necessários, em termos de pensamento, de progresso técnico, científico ou tecnológico e de organização social para que um determinado artefato material se prestasse a ser o meio de expressão elou registro do conteúdo verbal em questão. O que nos levaria então a acrescentar ao rol de questionamentos pertinentes a uma investigação científica na área da $\mathrm{AD}$ a seguinte pergunta: em que medida esta produção discursiva ou este conjunto de produções, que constituem o objeto da análise em questão, se viu condicionado no que tange à sua produção, transmissão e recepção por ter sido expressolregistrado em um SD específico e não em outro?

\section{Palavras finais}

Com base no exposto, julgamos que a midiologia se apresenta como uma relevante contribuição para os ED. Isto, posto que esta estabelece uma estreita conexão entre as ideias e a materialidade de seus vetores de transmissão; enquanto que se pressupõe similarmente nos ED uma conexão entre a produção linguística e, por um lado, as formações discursivas e ordens do discurso e, por outro, a configuração social, cultural, política e econômica das instâncias extradiscursivas. Quanto ao $\mathrm{SD}$, é evidente que assumirão proporções distintas em cada contexto de pesquisa o grau de determinação quanto a seu conteúdo verbal, bem como a relevância do contexto histórico mais amplo de progresso técnico que leve em conta a complexa trama produtiva e institucional que o tornou possível. Por fim, nos parece ser uma inquestionável exigência, em tempos de hipermediatização do cotidiano, a mais precisa compreensão possível dos papéis assumidos pelas novas tecnologias da informação e da comunicação no que tange à formação cultural, social, identitária e especialmente política dos indivíduos. 


\section{REFERÊNCIAS}

ACOSTA, María del Pilar Tobar Acosta \& RESENDE, Viviane de Melo. Gêneros e suportes: por um refinamento teórico dos níveis de abstração. Romanica Olomucensia, n.26.2, p. 127-142, 2014.

DEBRAY, Régis. Curso de midiologia geral. Tradução de Guilherme João de Freitas Teixeira. Petrópolis: Vozes, 1993.

DEBRAY, Régis. Manifestos midiológicos. Tradução de Guilherme João de Freitas Teixeira. Petropolis: Vozes, 1995.

DEBRAY, Régis. Introducción a la mediología. Barcelona: Paidós, 2001.

DIJK, Teun A. van. O giro discursivo. In: IÑIGUEZ, Lupicinio (coord.). Manual de análise do discurso em ciências sociais. Tradução de Vera Lúcia Joscelyne. Petrópolis: Editora Vozes. Prefácio, p. 7-14.

FAIRCLOUGH, N. Media discourse. Repr ed. London: Bloomsbury Academic, 1995.

FAIRCLOUGH, N. Analysing discourse: textual analysis for social research. London: Routledge, 2003.

IÑIGUEZ, Lupicinio. A linguagem nas ciências sociais: fundamentos, conceitos e modelos. In: IÑIGUEZ, Lupicinio (coord.). Manual de análise do discurso em ciências sociais. Tradução de Vera Lúcia Joscelyne. Petrópolis: Editora Vozes. Cap. 2, p. 50-104.

KALUME, Ana Carolina. Mediologia: a epistemologia da comunicação em Régis Debray. 2008. 121 f. Dissertação (Mestrado em Comunicação) - Faculdade de Comunicação, Universidade de Brasília, Brasília, 2008.

MAINGUENEAU, D. Les termes clés de l'analyse du discours. Paris: Seuil, 1996.

MAINGUENEAU, D. Análise de textos de comunicação. Tradução de Cecíllia P. de Souza-e-Silva e Décio Rocha. São Paulo: Corez Editora, 2004.

MARCUSCHI, L. A. Produção textual, análise de gêneros e compreensão. 3. ed ed. São Paulo: Parábola Ed, 2009. 
PÊCHEUX, Michel. Semantica e discurso: uma critica a afirmação do obvio. Tradução de Eni Pulcinelli Orlandi et al. Campinas: Ed. da UNICAMP, 1997.

PÊCHEUX, Michel. Análise de Discurso. Tradução de Eni Pulcinelli Orlandi et al. Campinas: Pontes Editores, 2014.

SAUSSURE, Ferdinand de. Curso de lingüística geral. Tradução de Antônio Chelini. São Paulo: Cultrix, 2006.

TÁVORA, Antônio Duarte Fernandes. Construção de um conceito de suporte: a matéria, a forma e a função interativa na atualização de gêneros textuais. 2008. 183 f. Tese (Doutorado em Linguística) - Centro de Humanidades, Universidade Federal do Ceará, Fortaleza, 2008.

VANDENBERGHE, Frédéric. Regis Debray and mediation studies, or how does an idea become a material force? Thesis Eleven, n. 89, p. 23-42, maio. 2007.

Recebido em: 30/11/2019

Aceito em: 05/04/2020 